\title{
IMPLEMENTASI FRAMEWORK COBIT 5 PADA SISTEM IFORMASI AKADEMIK
}

\section{Ripki Kristiawan, Rochmat Setiyawan}

Universitas Nusa Mandiri Jakarta, Indonesia

Email: ripkikristiawan1@gmail.com,rochmat_ron@nusamandiri.ac.id

\begin{abstract}
Abstrak
Penelitian yang dilakukan bertujuan untuk mengukur tingkat kapabilitas sistem informasi akademik terhadap ketercapaian visi dan misi kampus. Penelitian yang dilakukan meliputi studi pustaka, wawancara, penyebaran kuisioner, dan melakukan analisis terhadap hasil penyebaran kuisioner dan untuk mendapatkan nilai aktual dari tingkat kapabilitas sistem informasi akademik dan faktor yang mempengaruhi sistem informasi akademik. Peneliti menggunakan framework COBIT 5 pada 1 domain yaitu domain Monitor, Evaluate and Assess (MEA) untuk melakukan penelitian tentang kapabilitas sistem informasi akademik. Hasil dari penelitian ini menunjukan bahwa tingkat kematangan Teknologi Informasi (TI) sub domain MEAO1 mendapatkan indeks sebesar 3,72, sub domain MEAO2 sebesar 3,78 dan sub domain MEAO3 sebesar 3,80 sehingga diperoleh hasil rata rata maturity level pada domain $M E A$ saat ini mencapai nilai kematangan 3,77 (Predictable Process), kemudian dari hasil kematangan Teknologi Informasi berupa rekomendasi solusi untuk peningkatan kapabilitas sistem informasi akademik pada kampus. Kesimpulan hasil akhir pada penelitian ini, sistem informasi akademik pada kampus $\mathrm{T}$ sudah dapat terkelola dan terukur oleh kebutuhan pengguna, namun belum mencapai optimal dari kebutuhan pengguna.
\end{abstract}

Kata Kunci: COBIT 5; MEA; sistem informasi akademik

\section{Abstract}

This research aims to measure the level of academic information system capability towards the achievement of campus vision and mission. The research carried out includes literature study, interviews, distributing questionnaires, and analyzing the results of the questionnaire distribution and to get the actual value of the level of academic information system capability and the factors that affect the academic information system. Researchers use the COBIT 5 framework in 1 domain, namely the Monitor, Evaluate and Assess (MEA) domain to conduct research on academic information system capabilities. The results of this study indicate that the maturity level of Information Technology (IT) in the MEAO1 sub domain has an index of 3,72, the MEAO2 sub domain is 3,78 and the MEA03 sub domain is 3,80 so that the average maturity level in the MEA domain currently reaches a maturity value of 3,77 (Predictable). Process), then from the results of the maturity of Information Technology in the form of recommendations for solutions to increase the capability of academic information systems on campus. The conclusion of the final results in this study, academic information systems on campus $T$ can be managed and measured by the needs of users, but have not reached the optimal of user needs.

$\begin{array}{ll}\text { How to cite: } & \text { Kristiawan, R., Setiyawan, R., (2022) Implementasi Framework Cobit } 5 \text { pada Sistem Iformasi Akademik, } \\ & \text { Syntax Idea, 4(1), https://doi.org/10.36418/syntax-idea. v4i1.1737 } \\ \text { E-ISSN: } & 2684-883 \mathrm{X} \\ \text { Published by: } & \text { Ridwan Institute }\end{array}$


Keywords: COBIT 5, MEA, academic information systems

\section{Received: 2021-12-22; Accepted: 2022-01-05; Published: 2022-01-20}

\section{Pendahuluan}

Tata kelola teknologi informasi menggunakan COBIT framework telah banyak diteliti dan hasil rekomendasinya sudah banyak membantu perusahaan memperbaiki tata kelola teknologi informasi menjadi lebih baik. Seperti Penelitian (Candra, 2018) dengan judul analisa pengukuran tingkat kematangan sistem informasi akademik menggunakan COBIT di Politeknik X, (Agung \& Andry, 2019) dengan judul audit sistem informasi akademik pada universitas xyz menggunakan COBIT 5 pada domain MEA, (Pratama, 2019) dengan judul Audit Sistem Informasi Universitas Pendidikan Ganesha dengan Framework COBIT.

Salah satu bentuk implementasi Teknologi Informasi (TI) pada kampus yaitu Sistem Informasi Akademik (SIA). Teknologi Informasi diperlukan dalam pelaksanaan layanan akademik dapat mendukung kenyamanan, kemudahan, dan kecepatan dalam layanan akademik, sehingga layanan akademik yang berkualitas dapat diberikan kepada mahasiswa. Menurut (Cobit, 2015) COBIT mendefinisikan tujuan bisnis terkait dengan aktivitas teknologi informasi yang umumnya ada di perusahaan. Pada kerangka kerja COBIT hanya menjelaskan tujuan-tujuan bisnis (Chen et al., 2010) yang berkaitan dengan proses teknologi informasi.

Selain itu, persoalan mengenai pengelolaan data akademik menjadi poin yang sangat penting dan harus diperhatikan dengan baik supaya kegiatan perkuliahan dapat berjalan dengan lancar.

Upaya yang dilakukan Kampus $\mathrm{T}$ dalam mendukung pencapain visi misi lembaga untuk meningkatkan orientasi dan pelayanan pelanggan dengan mengimplementasikan aplikasi Sistem Informasi Akademik. Bertujuan untuk merubah pola proses administrasi akademik mahasiswa. Oleh karena itu sistem ini harus diaudit (Weber \& Hsee, 1999) untuk melihat sejauh mana sistem ini dapat berjalan, muai dari efektivitas dan kualitas semua proses sistem yang berjalan. Peneliti melakukan penelitian sistem informasi akademi pada Kampus T dengan menggunakan metode COBIT 5.

Pentingnya pendekatan audit dengan metode COBIT 5 pada penelitian ini dilakukan sekaligus untuk evaluasi dari sisi pengguna aplikasi sistem informasi akademik yang berjalan selama ini, sudah mengakomodir kebutuhan pengguna untuk melayani proses administrasi akademik. Pada tabel 1 terdapat komparasi dengan penelitian terkait implementasi COBIT pada sistem informasi.

Tabel 1

Penelitian terkait

\begin{tabular}{llllr}
\hline No & \multicolumn{2}{c}{ Penulis } & \multicolumn{3}{c}{ Hasil } \\
\hline 1 & $\begin{array}{l}\text { Menurut } \\
\text { 2019) }\end{array}$ & (Pratama, & $\begin{array}{l}\text { Implementasi COBIT pada sistem } \\
\text { informasi akademik dengan domain }\end{array}$ \\
& & DSS dan MEA. & \\
\hline
\end{tabular}




\begin{tabular}{lll}
\hline No & \multicolumn{1}{c}{ Penulis } & \multicolumn{1}{c}{ Hasil } \\
\hline 2 & $\begin{array}{l}\text { Agung, H., \& Andry, } \\
\text { J. F. (2019) }\end{array}$ & $\begin{array}{l}\text { Penerapan framework COBIT sistem } \\
\text { informasi akademik dengan domain } \\
\text { DSS. }\end{array}$ \\
\hline 3 & Efe, A. (2013). & $\begin{array}{l}\text { Penerapan COBIT 5 untuk Sistem } \\
\text { Agen e-Government Daerah Turkey. }\end{array}$ \\
\hline 4 & Krismiaji. (2015). & $\begin{array}{l}\text { Perbandingan Sistem Informasi pada } \\
\text { domain DS terkait kontrol internal IT } \\
\text { COBIT dengan SOP layanan akademik }\end{array}$ \\
& & S. \\
\hline 5 & $\begin{array}{l}\text { R. Wicaksono, } \\
\text { Handayaningsih. } \\
\text { (2013) }\end{array}$ & terkait penyampaian dan dukungan. \\
\hline
\end{tabular}

\section{Metode Penelitian}

Pemilihan metode penelitian ditentukan dengan menggunakan kerangka kerja COBIT 5 pada domain MEA (Monitor, Evaluate and Assess) dan dengan melakukan survey pada perusahaan dengan menggunakan metode kuesioner.

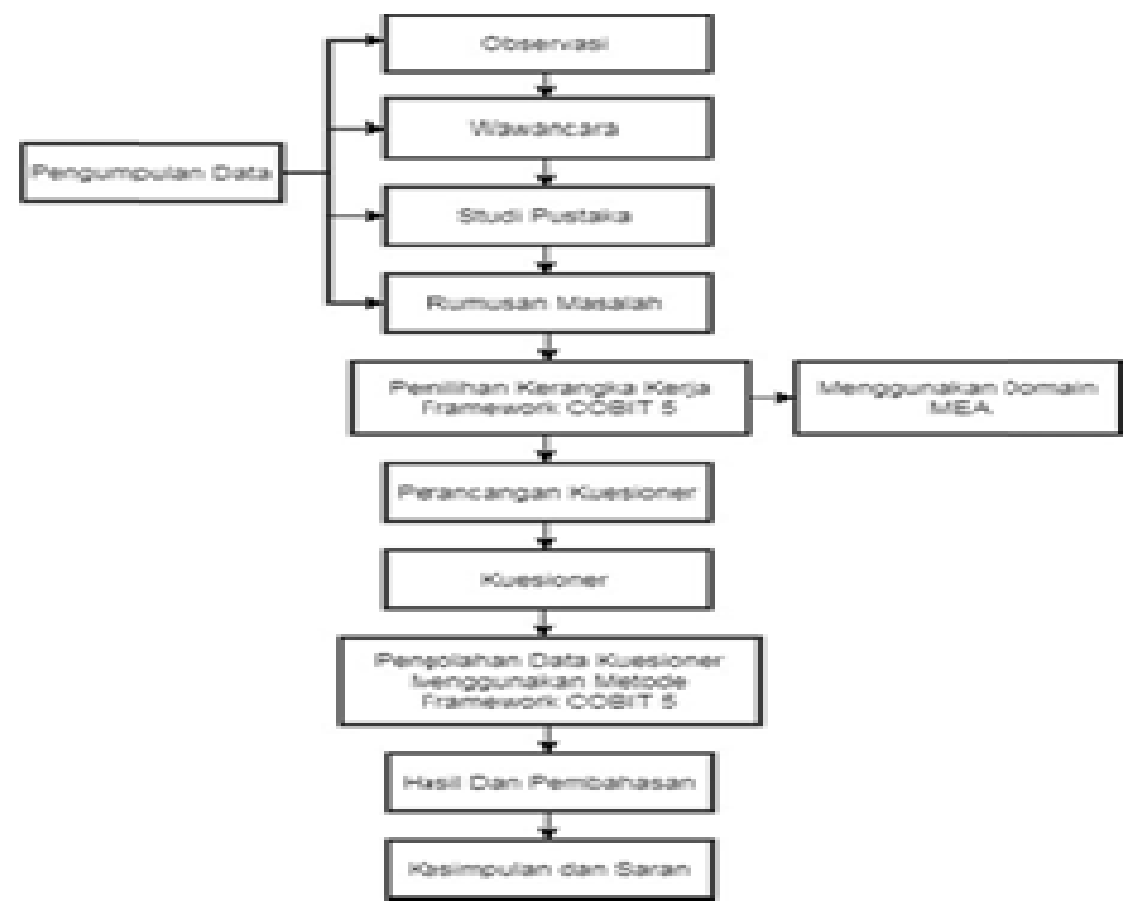

Gambar 1

Tahapan penelitian

Waktu penelitian dari bulan Mei hingga Juni 2021 dan tempat penelitian dilakukan di Kampus T. Alat yang digunakan penelitian ini adalah laptop dan bahan yang digunakan penelitian ini adalah menggunakan lembar kuisioner. Metode pengumpulan data yang dilakukan yaitu studi pustaka, observasi, dan wawancara.

Perancangan kuesioner dilakukan dengan berpedoman pada maturity model COBIT 5 (Idhom et al., 2016) yaitu dengan melihat nilai-nilai untuk menentukan tingkat 
maturity. Pertanyaan kueisioner menjelaskan setiap proses Domain MEA pada COBIT 5 yang dilakukan oleh pihak Kampus $\mathrm{T}$ berdasarkan jawaban responden seberapa besar tingkat kematangan dari setiap pertanyaan mulai dari skala 1 sampai 5. Dalam penelitian ini adalah bagian dari proccess yang menggunakan metode Ordinal Dengan model teknik pengukuran ordinal (Azizah, 2017) dalam pembuatan kuisioner menggunakan skala likert. Ukuran ordinal adalah angka yang diberikan dimana angka-angka tersebut mengandung pengertian tingkatan. Ukuran nominal digunakan untuk mengerutkan obyek dari tingkatan terendah sampai tertinggi. Ukuran ini tidak memberikan nilai absolut terhadap obyek, tetapi hanya memberikan urutan (rangking) saja. Set obyek (nilai rangking) diberi nomor $1=$ Sangat Tidak Setuju, 2 = Tidak Setuju, 3 = Ragu-Ragu, 4 = Setuju, dan 5 = Sangat Setuju. Sedangkan nilai absolut yang merupakan nilai model maturity diberi nomor $0=$ Proses Tidak Lengkap, $1=$ Proses Dijalankan, 2 = Proses Diatur, 3 = Proses Tetap, 4 = Proses Sudah di Ukur, $5=$ Proses Optimasi.

Pengolahan data kueisioner dilakukan dengan mencari nilai rata-rata setiap Sub Domain Pada Domain MEA yang terdiri dari MEA01, MEAO2 dan MEA03. Teknik analisis pada penelitian ini menggunakan rumus statistika untuk menghitung total poin dari setiap level maturity pada setiap variabel domain MEA yaitu MEA01, MEA02, dan $M E A 03$. Cara memperoleh penilaian setiap level dalam tiap variabel yaitu dengan mencari rata-rata keseluruhan tiap level, hasil dari analisis ini menentukan sejauh mana level maturity (Mulyadi, 2014) sistem informasi akademik Universitas T. Rumus statistika yang digunakan pada penelitian ini bisa di lihat pada rumus berikut:

\section{Nilai Maturity $=\left(\sum(\right.$ jawaban $x$ bobot $\left.)\right) /\left(\sum(\right.$ pertanyaan $\left.)\right)$}

Kemudian untuk Standar tingkat kematangan yang dijadikan standar Model Maturity merujuk pada dokumen ISACA seperti pada tabel 2. Tingkat Maturity Model (Efe, 2013).

\section{Tabel 2}

Level kematangan framework COBIT 5

\begin{tabular}{lll}
\hline $\begin{array}{c}\text { Index } \\
\text { Kematangan }\end{array}$ & \multicolumn{1}{c}{ Level Kematangan } \\
\hline $0-0.5$ & 0: Non Existent (Tidak Ada) & \\
\hline $0.51-1.5$ & 1: Initial /Ad Hoc (Inisial) & \\
\hline $1.51-2.5$ & $\begin{array}{l}\text { 2: Repeatable But Intuitive (Pengulangan proses } \\
\text { berdasarkan intuisi) }\end{array}$ & \\
\hline $2.51-3.5$ & 3: Defined Process (Proses telah didefinisikan) & \\
\hline $3.51-4.5$ & 4: Managed and Measurable (Dikelola dan terukur) \\
\hline $4.51-5$ & 5: Optimised (Optimalisasi) & \\
\hline
\end{tabular}

Setelah mengetahui tingkat kematangan saat ini dan tingkat kematangan yang diharapkan untuk mendapatkan tingkat kesenjangan berikut rumus yang digunakan: 


\section{Keterangan:}

\section{GAP Analyst=(A - B)}

$\mathrm{A}=$ Tingkat kematangan yang diharapkan

$\mathrm{B}=$ Tingkat kematangan saat ini

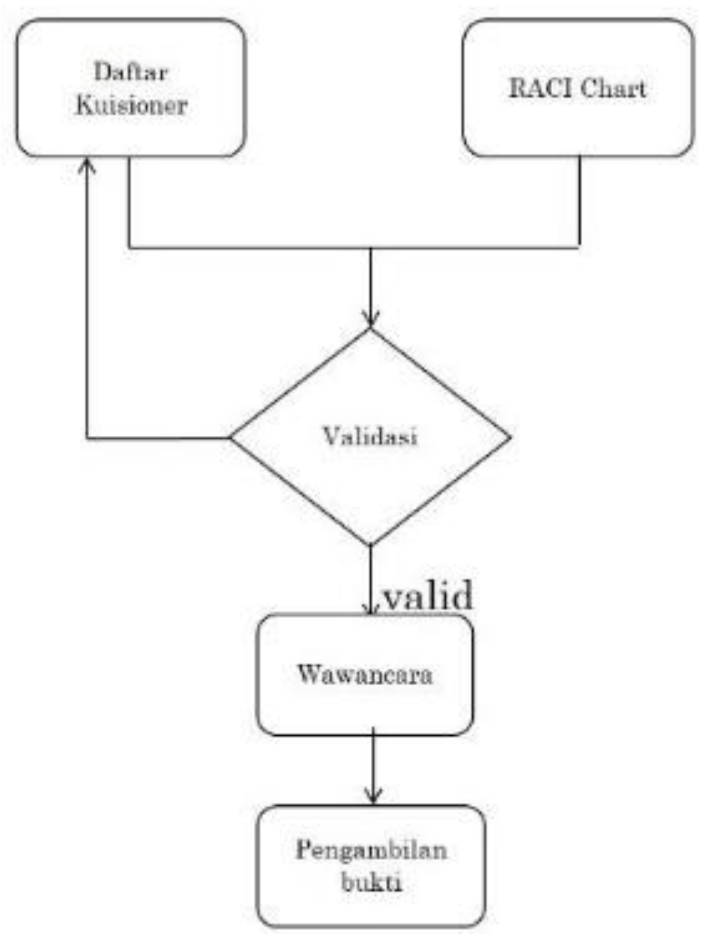

\section{Gambar 2}

Teknik Analisis Data

Teknik analisis data terdapat pada penelitian (Pasquini \& Galiè, 2013), berikut adalah langkah-langkah peneliti untuk melakukan pengumpulan data. Langkah awal dari teknis analisis data ini mulai dari menyiapkan daftar kuisioner, kemudian di sesuai atau di petakan dengan hasil diagram RACI supaya daftar kuisoner tepat dengan sasaran. Setelah itu melakukan validasi hasil kuisioner, apabila data kuisioner ada yang tidak valid maka kuisioner yang tidak valid diulang kembali sampai menghasilkan hasil valid. Kemudian setelah semua data valid maka dilakukan kroscek dengan melakukan wawancara ke pihak yang memiliki jabatan tinggi di Direktorat SISFO, kemudian disertai dengan pengambilan bukti.

\section{Hasil dan Pembahasan}

Menurut (Zuraidah, 2019) analisis data mencakup tentang penerapan dan pengukuran kinerja tingkat kematangan terhadap sistem informasi akademik pada Kampus T. Data yang didapat dari hasil observasi atau diperoleh di lapangan diolah sesuai metode framework COBIT 5. 
Tabel 3

Domain Pengukuran

\begin{tabular}{lll}
\hline Domain & Subdomain & Description \\
\cline { 2 - 3 } MEA01 & MEA01.01 & Establish a monitoring approach \\
\cline { 2 - 3 } & MEA01.03 & Set performance and conformance targets \\
\cline { 2 - 3 } & MEA01.04 & Analyse and report performance and conformance data \\
\cline { 2 - 3 } & MEA01.05 & Ensure the implementation of corrective actions \\
\hline & MEA02.01 & Monitor internal controls \\
\cline { 2 - 3 } MEA02.02 & Review business process controls effectiveness \\
\cline { 2 - 3 } MEA02.03 & Perform control self-assessments \\
\cline { 2 - 3 } MEA02.04 & Identify and report control deficiencies \\
\hline & MEA02.05 & Ensure that assurance providers are independent and \\
& & qualified \\
\hline & MEA02.06 & Plan assurance initiatives \\
\hline & MEA02.07 & Scope assurance initiatives \\
\hline MEA03.01 & Execute assurance initiatives \\
\hline MEA03.ify external compliance requirements \\
\cline { 2 - 3 } MEA03.03 & Optimise response to external requirements \\
\hline & MEA03.04 & Obtain assurance of external compliance \\
\hline
\end{tabular}

Dimulai dengan memperoleh data untuk mengetahui tingkat kematangan saat ini, dan melakukan wawancara untuk mengetahui tingkat kematangan yang diharapkan kedepan, sehingga akan diketahui selisih atau gap diantara tingkat kematangan saat ini dengan tingkat kematangan yang diharapkan. Hasil perhitungan dari domain MEAO1 adalah seperti ditampilkan pada tabel 4 .

Tabel 4

Hasil Perhitungan Domain MEA01

\begin{tabular}{|c|c|c|c|c|}
\hline Domain & Subdomain & Description & $\begin{array}{l}\text { Current } \\
\text { Maturity }\end{array}$ & Keterangan \\
\hline \multirow{4}{*}{ MEA01 } & MEA01.01 & $\begin{array}{l}\text { Establish } \\
\text { monitoring } \\
\text { approach }\end{array}$ & 3,64 & $\begin{array}{l}\text { 4: Managed and Measurable } \\
\text { (Dikelola dan terukur) }\end{array}$ \\
\hline & MEA01.02 & $\begin{array}{l}\text { Set performance } \\
\text { and conformance } \\
\text { targets }\end{array}$ & 3,69 & $\begin{array}{l}\text { 4: Managed and Measurable } \\
\text { (Dikelola dan terukur) }\end{array}$ \\
\hline & MEA01.03 & $\begin{array}{l}\text { Collect and } \\
\text { process } \\
\text { performance and } \\
\text { conformance } \\
\text { data }\end{array}$ & 3,7 & $\begin{array}{l}\text { 4: Managed and Measurable } \\
\text { (Dikelola dan terukur) }\end{array}$ \\
\hline & MEA01.04 & $\begin{array}{l}\text { Analyse and } \\
\text { report } \\
\text { performance }\end{array}$ & 3,63 & $\begin{array}{l}\text { 4: Managed and Measurable } \\
\text { (Dikelola dan terukur) }\end{array}$ \\
\hline
\end{tabular}




\begin{tabular}{cclcll}
\hline Domain & Subdomain & Description & $\begin{array}{l}\text { Current } \\
\text { Maturity }\end{array}$ & \multicolumn{1}{c}{ Keterangan } \\
\hline MEA01.05 & $\begin{array}{l}\text { Ensure the } \\
\text { implementation } \\
\text { of corrective } \\
\text { actions }\end{array}$ & 3,94 & $\begin{array}{l}\text { 4: Managed and Measurable } \\
\text { (Dikelola dan terukur) }\end{array}$ \\
\hline Rata-rata & & $\mathbf{3 , 7 2}$ & $\begin{array}{l}\mathbf{4 :} \\
\text { Measurable (Dikelola dan } \\
\text { terukur) }\end{array}$ \\
\hline
\end{tabular}

Hasil perhitungan dari domain MEAO2 adalah seperti ditampilkan pada tabel 5. Nilai current maturity tertinggi dengan capaian nilai 4 pada subdomain MEA02.05.

Tabel 5

Hasil Perhitungan dari domain MEA02

\begin{tabular}{|c|c|c|c|c|}
\hline Domain & Subdomain & Description & $\begin{array}{c}\text { Current } \\
\text { Maturit } \\
\mathbf{y} \\
\end{array}$ & Keterangan \\
\hline \multirow{9}{*}{ MEA02 } & MEA02.01 & $\begin{array}{l}\text { Monitor internal } \\
\text { controls }\end{array}$ & 3,79 & $\begin{array}{l}\text { 4: Managed and Measurable } \\
\text { (Dikelola dan terukur) }\end{array}$ \\
\hline & MEA02.02 & $\begin{array}{l}\text { Review business } \\
\text { process controls } \\
\text { effectiveness }\end{array}$ & 3,8 & $\begin{array}{l}\text { 4: Managed and Measurable } \\
\text { (Dikelola dan terukur) }\end{array}$ \\
\hline & MEA02.03 & $\begin{array}{l}\text { Perform control } \\
\text { self-assessments }\end{array}$ & 3,75 & $\begin{array}{l}\text { 4: Managed and Measurable } \\
\text { (Dikelola dan terukur) }\end{array}$ \\
\hline & MEA02.04 & $\begin{array}{l}\text { Identify and } \\
\text { report control } \\
\text { deficiencies }\end{array}$ & 3,71 & $\begin{array}{l}\text { 4: Managed and Measurable } \\
\text { (Dikelola dan terukur) }\end{array}$ \\
\hline & MEA02.05 & $\begin{array}{ll}\text { Ensure } & \text { that } \\
\text { assurance } & \\
\text { providers } & \text { are } \\
\text { independent } & \text { and } \\
\text { qualified } & \\
\end{array}$ & 4 & $\begin{array}{l}\text { 4: Managed and Measurable } \\
\text { (Dikelola dan terukur) }\end{array}$ \\
\hline & MEA02.06 & $\begin{array}{l}\text { Plan assurance } \\
\text { initiatives }\end{array}$ & 3,83 & $\begin{array}{l}\text { 4: Managed and Measurable } \\
\text { (Dikelola dan terukur) }\end{array}$ \\
\hline & MEA02.07 & $\begin{array}{l}\text { Scope assurance } \\
\text { initiatives }\end{array}$ & 3,65 & $\begin{array}{l}\text { 4: Managed and Measurable } \\
\text { (Dikelola dan terukur) }\end{array}$ \\
\hline & MEA02.08 & $\begin{array}{l}\text { Execute } \\
\text { assurance } \\
\text { initiatives }\end{array}$ & 3,69 & $\begin{array}{l}\text { 4: Managed and Measurable } \\
\text { (Dikelola dan terukur) }\end{array}$ \\
\hline & Rata-rata & & 3,78 & $\begin{array}{l}\text { 4: Managed and Measurable } \\
\text { (Dikelola dan terukur) }\end{array}$ \\
\hline
\end{tabular}

Hasil perhitungan dari domain MEAO3 adalah seperti ditampilkan pada tabel 6 . Nilai tertinggi pada domain MEAO3 didapat pada subdomain MEA03.03 dengan nilai current maturity 3,94. Nilai terendah didapat pada subdomain MEA03.01 dengan nilai current maturity 3,71 . 
Tabel 6

Hasil Perhitungan Domain MEA03

\begin{tabular}{|c|c|c|c|c|}
\hline Domain & Subdomain & Description & $\begin{array}{c}\text { Current } \\
\text { Maturit } \\
\mathbf{y}\end{array}$ & Keterangan \\
\hline \multirow{5}{*}{ MEA03 } & MEA03.01 & $\begin{array}{l}\text { Identify external } \\
\text { compliance } \\
\text { requirements }\end{array}$ & 3,71 & $\begin{array}{l}\text { 4: Managed and Measurable } \\
\text { (Dikelola dan terukur) }\end{array}$ \\
\hline & MEA03.02 & $\begin{array}{l}\text { Optimise } \\
\text { response } \\
\text { external } \\
\text { requirements }\end{array}$ & 3,75 & $\begin{array}{l}\text { 4: Managed and Measurable } \\
\text { (Dikelola dan terukur) }\end{array}$ \\
\hline & MEA03.03 & $\begin{array}{l}\text { Confirm external } \\
\text { compliance }\end{array}$ & 3,94 & $\begin{array}{l}\text { 4: Managed and Measurable } \\
\text { (Dikelola dan terukur) }\end{array}$ \\
\hline & MEA03.04 & $\begin{array}{l}\text { Obtain assurance } \\
\text { of } \quad \text { external } \\
\text { compliance }\end{array}$ & 3,79 & $\begin{array}{l}\text { 4: Managed and Measurable } \\
\text { (Dikelola dan terukur) }\end{array}$ \\
\hline & Rata-rata & & 3,8 & $\begin{array}{l}\text { 4: Managed and Measurable } \\
\text { (Dikelola dan terukur) }\end{array}$ \\
\hline
\end{tabular}

Hasil perhitungan rata-rata setiap domain $M E A$ adalah seperti yang ditampilkan pada tabel 7. Komparasi diantara masing-masing domain $M E A$ berkisar di angka current maturity $3,72-3,8$.

Tabel 7

Rata rata $M E A$

\begin{tabular}{|c|c|c|c|}
\hline Domain & Description & $\begin{array}{c}\text { Current } \\
\text { Maturit } \\
\mathbf{y}\end{array}$ & Keterangan \\
\hline MEA01 & $\begin{array}{lr}\begin{array}{l}\text { Monitor, Evaluate, } \\
\text { and Asses }\end{array} \\
\text { Perfomance } \\
\text { Conformance }\end{array}$ & 3,72 & $\begin{array}{l}\text { 4: Managed } \quad \text { and } \\
\text { Measurable (Dikelola dan } \\
\text { terukur) }\end{array}$ \\
\hline MEA02 & $\begin{array}{l}\text { Monitor, Evaluate, } \\
\text { and Asses the } \\
\text { system of Internal } \\
\text { Control }\end{array}$ & 3,78 & $\begin{array}{l}\text { 4: Managed } \text { and } \\
\text { Measurable (Dikelola dan } \\
\text { terukur) }\end{array}$ \\
\hline MEA03 & $\begin{array}{lr}\text { Monitor, } & \text { Evaluate } \\
\text { and } & \text { Assess } \\
\text { Compliance } & \text { with } \\
\text { External } & \\
\end{array}$ & 3,80 & $\begin{array}{l}\text { 4: Managed } \text { and } \\
\text { Measurable (Dikelola dan } \\
\text { terukur) }\end{array}$ \\
\hline Rata-rata & & 3,77 & $\begin{array}{l}\text { 4: Managed and } \\
\text { Measurable (Dikelola dan } \\
\text { terukur) }\end{array}$ \\
\hline
\end{tabular}

Nilai rata-rata current maturity dari ketiga domain MEA yang diperoleh pada tabel 8 sebesar 3,77. Pada nilai current maturity tersebut merujuk pada identifikasi 
keterangan Managed and Measurable, yang artinya survei terkait sistem informasi dikelola dan terukur.

\section{Tabel 8}

Perbandingan current maturity, expected maturity dan gap

\begin{tabular}{lcll}
\hline & \multicolumn{3}{c}{ Maturity Level } \\
\cline { 2 - 4 } Domain & $\begin{array}{c}\text { Current } \\
\text { Maturity }\end{array}$ & $\begin{array}{l}\text { Expecte } \\
\mathbf{d}\end{array}$ & Gap \\
& & $\begin{array}{l}\text { Maturit } \\
\text { y }\end{array}$ & \\
\hline MEA01 & 3,72 & 4 & 0,28 \\
\hline MEA02 & 3,78 & 4 & 0,22 \\
\hline MEA03 & 3,80 & 4 & 0,2 \\
\hline Rata-rata & $\mathbf{3 , 7 7}$ & $\mathbf{4}$ & $\mathbf{0 , 2 3}$ \\
\hline
\end{tabular}

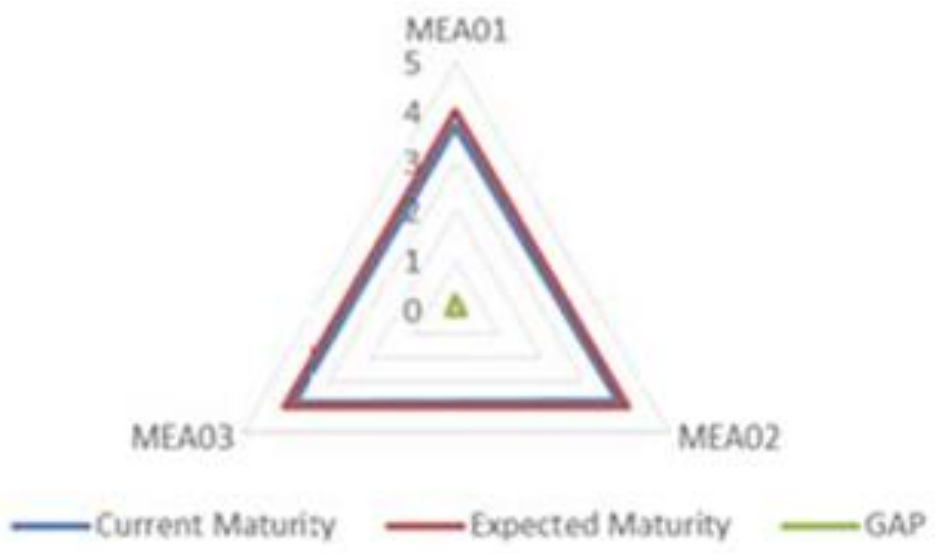

Gambar 3

\section{Grafik Nilai Maturity Domain $M E A$}

Hasil perhitungan rata-rata current maturity MEA01, MEA02, MEA03 sebesar 3,77 sedangkan selisih yang didapat sebesar 0,23 seperti grafik pada gambar 2. Berdasarkan hasil pengurukuran tersebut akan diidentifikasi berdasarkan domain MEA01, MEA02 dan MEA03. Framework COBIT 5 dapat memberikan perbaikan sistem di Kampus T.

\section{Kesimpulan}

Berdasarkan penelitian yang telah dilakukan di perguruan Kampus $\mathrm{T}$ dengan framework COBIT 5 pada domain MEA, mendapatkan hasil tingkat kematangan. Sedangkan pada audit yang dilakukan SIA berada pada level 3,77 dimana proses yang sekarang diterapkan menggunakan proses yang sudah terkelola dan terstrukur baik secara kualitatif maupun kuantitatif, sudah diperiksa, dievaluasi dan dianalisis untuk mencapai tujuan kedepannya untuk mengetahui keseluruhan penilaian, domain pada COBIT 5 harus digunakan seluruhnya supaya nantinya tata kelola dan manajemen dapat saling terintegrasi. 


\section{BIBLIOGRAFI}

Agung, H., \& Andry, J. F. (2019). Audit Sistem Informasi Akademik Pada Universitas XYZ Menggunakan COBIT 5 Pada Domain Deliver, Service \& Support (DSS). Prosiding Semnastek 2019, 1(1).Google Scholar

Azizah, N. (2017). Audit Sistem Informasi Menggunakan Framework COBIT 4.1 Pada E-Learning UNISNU Jepara. Simetris: Jurnal Teknik Mesin, Elektro Dan Ilmu Komputer, 8(1), 377-382. Google Scholar

Candra, M. (2018). Aspek Perlindungan Anak Indonesia. Prenada Media. Google Scholar

Chen, S., Osaka, A., Hayakawa, S., Shirosaki, Y., Matsumoto, A., Fujii, E., Kawabata, K., \& Tsuru, K. (2010). One-step preparation of organosiloxane-derived silica particles. Advances in Bioceramics and Porous Ceramics II-33rd International Conference on Advanced Ceramics and Composites, 3-15. Google Scholar

Cobit, I. M. (2015). Jurnal Informasi Volume VII No.2 / November / 2015. Jurnal Informasi Volume VII No.2 / November / 2015, 7(2), 33-47.

Efe, A. (2013). COBIT-5 Framework as a model for the regional development agencies in Turkey. International Journal Of Ebusiness And Egovernment Studies, 33-43. Google Scholar

Idhom, M., Irwansyah, I., \& Alit, R. (2016). Analisis Sumber Daya Manusia Teknologi Informasi Menggunakan Kerangka Kerja COBIT 4.1 (Studi Kasus: Unit Pelaksana Teknis Telematika Universitas Pembangunan Nasional "Veteran" Jawa Timur). Kinetik: Game Technology, Information System, Computer Network, Computing, Electronics, and Control, 101-106. Google Scholar

Mulyadi. (2014). Auditing (Edisi 6). Salemba Empat.Yogyakarta

Pasquini, A., \& Galiè, E. (2013). COBIT 5 and the Process Capability Model. Improvements Provided for IT Governance Process. Proceedings of FIKUSZ, 13, 67-76. Google Scholar

Pratama, P. A. (2019). Audit Sistem Informasi Universitas Pendidikan Ganesha Dengan Framework Cobit 5. Universitas Pendidikan Ganesha. Google Scholar

Weber, E. U., \& Hsee, C. K. (1999). Models and mosaics: Investigating cross-cultural differences in risk perception and risk preference. Psychonomic Bulletin \& Review, 6(4), 611-617. Google Scholar

Zuraidah, E. V. A. (2019). Audit Sistem Informasi Sumber Daya Manusia Menggunakan COBIT 4.1 Pada Perusahaan Spareprat mobil PT. XYZdi Jakarta. PROSISKO: Jurnal Pengembangan Riset Dan Observasi Sistem Komputer, 6(2). Google Scholar 
Implementasi Framework Cobit 5 pada Sistem Iformasi Akademik

\section{Copyright holder:}

Ripki Kristiawan, Rochmat Setiyawan (2022)

\section{First publication right:}

Syntax Idea

This article is licensed under:

(c) (i) (2) 